Melodie J. Fox. 2011. Prototype theory: An alternative concept theory for categorizing sex and gender? In Smiraglia, Richard P., ed. Proceedings from North American Symposium on Knowledge Organization, Vol. 3. Toronto, Canada, pp. 151-159.

\author{
Melodie J. Fox (msjoblad@uwm.edu) \\ University of Wisconsin, Milwaukee, Milwaukee, WI USA,
}

\title{
Prototype Theory: An Alternative Concept Theory for Categorizing Sex and Gender?*
}

\begin{abstract}
Classical theories of classification and concepts, originating in ancient Greek logic, have been criticized by classificationists, feminists, and scholars of marginalized groups because of the rigidity of conceptual boundaries and hierarchical structure. Despite this criticism, the principles of classical theory still underlie major library classification schemes. Rosch's prototype theory, originating from cognitive psychology, uses Wittgenstein's “family resemblance” as a basis for conceptual definition. Rather than requiring all necessary and sufficient conditions, prototype theory requires possession of some but not all common qualities for membership in a category. This paper explores prototype theory to determine whether it captures the fluidity of gender to avoid essentialism and accommodate transgender and queer identities. Ultimately, prototype theory constitutes a desirable conceptual framework for gender because it permits commonality without essentialism, difference without eliminating similarity. However, the instability of prototypical definitions would be difficult to implement in a practical environment and could still be manipulated to subordinate. Therefore, at best, prototype theory could complement more stable concept theories by incorporating contextual difference.
\end{abstract}

*Also published as: Fox, Melodie J. 2011. Prototype Theory: An Alternative Concept Theory for Categorizing Sex and Gender? Knowledge Organization 38: 328-34.

\subsection{Introduction}

Classical theories of classification and concepts, originating in ancient Greek logic, have been roundly criticized by classificationists, feminists, and scholars of marginalized groups because of the rigidity of conceptual boundaries and hierarchical structure, rife with implications of dominance and subordination (Olson 2001, 2007). While classical theory works well in simple situations, human experience is faced with ambiguity, inconsistency and incompleteness of information, as the world is dynamic and full of overlap. Classical theory struggles to handle epistemological variation, especially with complex, socially-influenced categories, such as groupings of people. The options are to either erase difference, to fudge over complexity, or to classify so closely that the categories are tiny. Despite criticism, in LIS, classical theory still underlies the major classification systems.

Perhaps the problem lies not in the categorization of humans, but rather in the concept of a concept. Concepts facilitate the ability to categorize and thus understand and predict the material world, yet disagreement exists on what formulates a concept. Most scholarly work about concepts begins with the acknowledgement that a satisfactory overall theory of concepts does not exist and would be difficult to conceive. It is not my purpose to come up with a complete concept theory. Rather, I will analyze one of the existing concept theories to determine how it handles slippery and sensitive concepts for which categorization has real consequences: sex and gender. 
At a cognitive level, classification helps humans function by reducing what we see into concepts, allowing us to recognize like items, thus shortening processing time as we move through our day. Often, the shortcuts that concepts provide can blur significant differences within a category, particularly when classifying people. For those who fall in the borderland between male and female or those who resist the gendered behavior socially prescribed for their sex, the mutually exclusive gender categories afforded by classical theory can cause social and emotional consequences. A broader cultural understanding of sex and gender can influence systemic discourses whether in legal, medical, social, educational, or information environments. This paper, focusing on the theoretical, is the first stage of ongoing research exploring different ways to categorize sex and gender.

Would the concepts of sex or gender change if the concept of concepts changed? To investigate, I undertake three tasks that Haslanger (2000,33) calls conceptual, descriptive and analytical inquiries. For the conceptual inquiry, I will explore prototype theory as an alternative or supplementary concept theory to determine if it would be a viable option for defining sex and gender in ways that reflect the diversity that classical concept theory cannot capture. For the descriptive inquiry, I will use Jacob Hale’s $(1996,290)$ "Defining Characteristics of the Category Woman" as an example of a gender prototype. And for the analytical approach, I will discuss the implications of a different concept theory for sex and gender. At first blush, prototype theory constitutes a desirable conceptual framework for gender because it permits commonality without essentialism, difference without eliminating similarity. However, the instability of prototypical definitions would cause difficulty in a practical environment. Therefore, at best, prototype theory could complement more stable concept theories by incorporating contextual difference.

\subsection{Concept theory}

The study of concepts dates back to ancient Greek philosophy, and debates persist over the philosophical, psychological, metaphysical, linguistic, epistemological and cognitive implications of concepts (Margolis and Lawrence, 2006). Generally speaking, concepts are universals whose particulars reside together in a category. Concepts do not have a one-to-one relationship with language, as different terms can be used to express the same concept. The structure of concepts is determined by what irreducible conditions the concept requires and how those parts are established.

\subsection{Classical concept theory}

Classical concept theory relies on the classical logic of Parmenides and Plato, further developed by Aristotle in the fourth century BCE. Many scholars have critiqued classical theory's focus on hierarchy, mutual exclusivity, and the inherent essentialism of its conceptual structure, all qualities inhospitable to classifying people. Andrea Nye (1990) and Hope Olson $(1999,2007)$ have tracked the evolution from Platonic divisions to Aristotelian classification from a feminist perspective in detail, so this paper will only provide a rudimentary overview to supply some supporting information and a basis for comparison.

In classical concept theory, "a concept is a summary representation of some sets of things in terms of conditions that are singly necessary and jointly sufficient for determining membership in that set” (Hjørland 2009, 1520-1521). Parmenides first introduced divisions between concepts based on difference, expressed as sets of A/not A. All items in set A possess 
Melodie J. Fox. 2011. Prototype theory: An alternative concept theory for categorizing sex and gender? In Smiraglia, Richard P., ed. Proceedings from North American Symposium on Knowledge Organization, Vol. 3. Toronto, Canada, pp. 151-159.

the conditions or qualities outlined in the definition of the concept. Although classical theory purports to name an extant, orderly nature, the qualities or conditions selected to determine difference generally are based on the goal of the classification scheme (Olson 1999, 69). The traits chosen might be arbitrary, chosen to simplify the classification process, or for more specious reasons, such as to deliberately classify an item or group into a subordinate position.

Plato intended for impermeable walls to partition concept sets. The divisions are governed by three laws, leading to mutual exclusivity: the Law of Non-contradiction: Nothing can be both A and Not-A; the Law of Identity: Whatever is A is A; and the Law of the Excluded Middle: Everything is either A or Not-A (Olson 2007, 511). Mutual exclusivity requires that an item cannot partially be a member of a set or a member of two sets simultaneously; membership is all or nothing. Not $\mathrm{A}$ is not the opposite of $\mathrm{A}$, but rather the absence of $\mathrm{A}$. An item that does not possess all required qualities would have no value. No credit is awarded for being "kind of like" the other items in the set.

Classical theory's rigidity does not allow for the shifting nature of social categories and in fact intends for conceptual definitions to be isolated from context (Slaughter 1988, 9). Frye (2005, 48-49) insists that "social categories are not sets, and thinking of them as sets is disastrous." She differentiates social categories from Plato's strict divisions by writing, "however social categories work ... they do it without having boundaries fixed by necessary and sufficient conditions and consequently without having any absolute sameness as their principle of coherence" (49, emphasis hers). Campbell $(2000,127)$ speaking of gay and lesbian communities through the framework of Sedgwick suggests, "people are different, categories shift, and labels are provisional. We are dealing with no monolithic identity, no stable categories, and no consensus." Social sets, then, are unstable entities that contain a variety of similar members, with shifting and porous boundaries.

\subsection{Prototype theory}

Prototype theory provides a more hospitable environment for social categories. Wittgenstein (1988) designates "family resemblance" as the thread that constructs the fabric of a concept. He acknowledges the difference that occurs within categories: "For if you look at them you will not see something common to all, but similarities, relationships, and a whole series of them," a "complicated network of similarities overlapping and criss-crossing” (Wittgenstein 1988, 66). The abstract conceptualizations provided through classical concept theory are too vague to really discern the meaning of a word. Instead, context is required to recognize how the word is being used. Wittgenstein calls the shifting of meaning "language games," and this idea helped shape prototype theory as developed by Rosch.

Rosch's (1999) prototype theory of concepts, originating in cognitive psychology, also decides membership in a category through possession of particular properties, but group membership does not require possession of all qualities - just enough for the fabric of the concept to hold together. Just as Wittgenstein believed, context determines the meaning of a word or what conditions are in place at a particular moment to define the concept. Qualities of a concept are incidental, rather than essential. The member probably will possess all features typical to the group, but if it possesses some but not all, it still retains membership in the group. Unlike a universal scheme where concepts are defined the same every time, concepts are defined "only in actual situations in which they function as participating parts of the situation rather than as either representations or as mechanisms for identifying options” (61). Membership in a 
Melodie J. Fox. 2011. Prototype theory: An alternative concept theory for categorizing sex and gender? In Smiraglia, Richard P., ed. Proceedings from North American Symposium on Knowledge Organization, Vol. 3. Toronto, Canada, pp. 151-159.

category can be determined by resemblance to an ideal exemplar or by possession of a sufficient number of the typical features of the class. A prototype might be either a "paragon" or an "average" member of the group, and the prototype differs between individuals and moments, making it contextually variant. A concept might also contain multiple prototypes. The prototype anchors the ideational content of the concept, but does not exclude variants, nor does it deem difference as deviant.

\subsection{Concept theory in KO}

In knowledge organization, Hjørland (2009) describes concepts as products of specific disciplinary domains and argues that differing knowledge organizations systems can co-exist based on different conceptualizations found in different domains. A classification scheme should be "linked to certain discourses and interests," acknowledging historical and paradigmatic associations (1529). While Hjørland's view is appealing and could work well within specialized libraries, it has been criticized for building obstacles for interdisciplinary research (Szostak 2010), and its usefulness in universal settings, such as public libraries, merits further investigation.

Szostak (2004) proposes instead a universal scheme for classifying science that breaks complex concepts down into the most basic “constituent parts," upon which scientists can agree, therefore making concepts accessible across disciplines. Szostak's view is contingent upon belief in universal concepts, which can be incompatible with postmodern epistemologies. Dahlberg $(1995,22)$ adheres to the classical formula, where essential qualities are outlined in defining a concept. She calls her approach the "analytical, referent-oriented" concept theory, where the analysis must be based on an "item of reference." In her model of concept construction, "correct statements" must be made about the item; however, "correct" statements may be difficult to verify unless, again, a belief in universal truths exists. Bowker and Star (1999) believe that humans use both classical theory and prototype theory when classifying. Classical theory provides universality and stability, and prototype theory accommodates the fuzziness of sociallydetermined variance. They write that classification "involve[s] politics, kinds both prototypical and Aristotelian... and deletion of the practices in the production of the final formal record" (66). Jacob $(2004,537,522)$ makes a similar distinction between categorization, which is "flexible and creative," and classification, which is "artificial and arbitrary.”

\subsection{The Concept of Woman}

The current state of feminism resists classical conceptions of woman and has taken a tactic similar to Hjørland's domain-centric approach, where each theory produces an eristic concept of woman not always compatible with those of other theories. In the discipline of gender studies, gender has been defined as a social construct, quirk of psychosocial development, biological set, inconsequential human trait, performance, sociolinguistic activity, and self-perpetuating illusion, among others. As Mikkola $(2009,560)$ legitimately points out, questions about the definition of “woman” are puzzling to most people: “Aren’t women simply female humans?” But the multitude of definitions has proliferated to challenge stereotypical views about women that have become entrenched in culture. Spelman $(1988,134)$ writes, “'Women' are what females of the human species become, or are supposed to become, through learning how to think, act, and live 
Melodie J. Fox. 2011. Prototype theory: An alternative concept theory for categorizing sex and gender? In Smiraglia, Richard P., ed. Proceedings from North American Symposium on Knowledge Organization, Vol. 3. Toronto, Canada, pp. 151-159.

in certain ways.” In other words, the definition of woman is disputed because of non-essential cultural influences imposed upon the female sex.

Because of the fear of essentialism, separating sex from gender has also been important to feminists, yet the relationship is nearly inextricable. As commonly understood, "sex" implies a biological division between those who have female and male sex organs. "Gender," then, reflects the social or cultural influences on sexual difference. Feminists assert that biological difference is exploited by patriarchal society to justify fitness for gender roles, which almost exclusively place women subordinate to men. Frye $(2005,44)$ points out that essentialism permeates classification, but "the word female has been virtually banished from the discourse of...feminist theory" because of fear of biological determinism. Similarly, Olson (2007) argues that despite Plato's intentions, the A/Not A division often morphs into A/B, with B representing the opposite of A. If A is "men," they automatically may be culturally ascribed conditions such as strength and rationalism, which means "women" involuntarily become B, with traits of weakness and emotion. When group members do not possess, do not believe they possess, or do not want the traits associated with the group, the dilemma becomes, as Alcoff $(1995,434)$ notes, "our very self-definition is grounded in a concept that we must deconstruct and de-essentialize in all of its aspects." Women do not want to be pigeonholed as possessing one trait or another, as yet by falling under the name of "woman," something must connect them, and most often that something has been the female sex.

Complicating the sex-gender division are the gender and sex identities that differ from or resist the heteronormative or mainstream binary biological divisions. The biological division between sexes is not nearly as clear-cut as most people assume. Research surveying medical literature between 1953 and 2000 reports that " $1.7 \%$ of live births do not conform to the Platonic ideal of absolute sex chromosomal, gonadal, genital and hormonal dimorphism.” They also estimate that about 1-2 out of every 1000 live births undergo "corrective" surgery in order to conform the genitals to one sex or the other, which can cause gender confusion later in life (Blackless, et al. 2000, 161). Because of discomfort with categorical ambiguity, Hale $(1996,288)$ writes that babies "born with 'ambiguous' genitals are assigned to a sex as soon as possible," usually before eighteen months old. Furthermore, Halberstam (1994) identifies a multitude of self-categorizations within the queer community that explode the binaries of homosexual/heterosexual, as well as male/female and man/woman.

\subsection{Applying Prototype Theory to Sex and Gender}

Does defining a concept automatically seal the boundaries of the category? Chow (1993, 15, her emphasis) asks, “isn't "naming" precisely the centering, the essentializing act?” Chow's use of the word "centering” suggests prototype theory, where a center exists, but with permeable rather than rigid boundaries. If feminists and queer theorists reject the hierarchical model of concepts because it subordinates and traps them within someone else's structure, why not try a different model that rejects essentialism and mutual exclusivity? Although gender and sex are fluid in reality, current cultural standards are constrained by the man/woman binary, so those of ambiguous gender generally end up in one category or another based on outward appearance. However, Haslanger (2000, 38) writes that if gender is considered "social position, we must allow that one can be a woman without ever acting... [or] feeling like a woman, or even having a female body.” A prototype conceptualization would find that indeed a network of qualities common to "woman" exist, yet none of those qualities are required or even central, provided 
some of the other features typical to the class are present. It should be noted that possession of the qualities does not automatically place one in the category "woman," i.e. a male in an occupation acceptable for a woman does not make him a woman. A woman usually, but not always dresses in a feminine fashion. A woman usually, but not always, has female sex organs. Thus, the concept avoids essentialist determinism, yet acknowledges similarity.

\subsection{Hale's "Defining Characteristics of the Category Woman”}

What are the qualities that might work for a conceptualization of "woman?" Although not intentionally working within a prototype framework, Hale (1996, 290) provides 13 characteristics that could determine membership in the category "woman," but specifically states, "None of these characteristics is a necessary or sufficient condition." The first five cover characteristics typically associated with sex. Hale weights these qualities more heavily, since culturally, the presence of biological sex is considered the most important.

1. Absence of a penis

2. Presence of breasts

3. Presence of reproductive organs

4. Presence of estrogen and progesterone in within the appropriate range for age

5. Presence of XX or absence of Y chromosomes (290-291)

The next cluster of characteristics refer to cultural expectations for the gender of woman and the idea of identity. Hale asks, "Do you feel yourself to be a woman? Then, according to this defining characteristic, you are” (292).

6. Having a gender identity as a woman

7. Having an occupation considered acceptable for a woman.

8. Engaging in leisure pursuits considered to be acceptable for a woman

9. Engaging in a form of sexual/affectional relationship with a man commonly recognized as a heterosexual, who does not identify as gay or bisexual

The next set has to do with looking and acting like a woman according to cultural norms. This is the most difficult to achieve for male-to-female transgenders who strive to "pass" as a woman.

10. Achieving and maintaining a physical gender self-presentation of a woman

11. Behaving in ways that produce the gender assignment "woman" to those with whom one interacts

12. Giving textual clues to produce the gender assignment "woman," such as using female pronouns to refer to oneself, having documents that bear the designation " $F$," and having a feminine name. (293)

Hale asks if people with whom one interacts unambiguously think she's a woman? If so, she's a woman. And finally:

13. Having a history consistent with the gender assignment "woman" that provides an unbroken line from female infancy to womanhood.

Collapsing together the social and the biological, “woman” becomes more inclusive of identities located on the border of gender categories. 
Melodie J. Fox. 2011. Prototype theory: An alternative concept theory for categorizing sex and gender? In Smiraglia, Richard P., ed. Proceedings from North American Symposium on Knowledge Organization, Vol. 3. Toronto, Canada, pp. 151-159.

\subsection{Discussion/Implications}

But what if one believes that "woman" cannot possibly have a penis? The inclusiveness afforded by prototypes eliminates the either/or binary constraint demanded by classical concept theory; however, the individual nature backfires, where belief systems exclude particular traits. Prototypes are formed in any number of ways - frequency of perception, personal preferences and beliefs, culture, goals, and experience, among others. Indeed, an issue with prototype theory is the notion of the prototype as an ideal representative of the set. $\operatorname{Rosch}(1999,65,71)$ places value judgments on members of the group by grading them as "good" representatives (closer family resemblance to the prototype) or "bad" (least resemblance to prototype). This could lead to devaluation of instantiations that do not closely match that prototype, particularly if the "paragon" approach is used. In the case of gender, the "average" rather than "exemplar" version of a prototype would work best, since no ideal exemplar exists. Hale (1996, 283), too, warns that women behaving in ways not compatible with a paragon may not be considered "a real woman."

And what is meant by “acceptable for a woman?” What is “acceptable for a woman” is tied to current cultural expectations, rendering the concept contextually dynamic, but circular. Rosch $(1999,71)$ calls the formation of concepts "situation based and participatory." Therefore, a more inclusive prototype relies on the provision of models for people to perceive that influence their individual prototypes. In a homogenous society that lacks diversity of imagery or messages, what is "acceptable for a woman" may be limited, but other situational factors can neutralize the dominant impressions. In persistently oppressive societies or in situations where individuals live in isolation from outside influence, conceptualizations might resist change, but as a whole, prototype theory would allow for dynamic, historically current concepts. Contrasting messages would be most evident and influential in societies where widespread access to information is available.

\subsection{Conclusion}

Prototype theory might work on a theoretical or psychological plane, but could it work as a technique for knowledge organization? The dynamic and personal nature of prototypes presents some problems for classification systems that require brevity in conceptual representation and some degree of stability. As normative notions, concepts still can be subject to the "tyranny of the majority," or risk being constructed by those in power, similar to other concept theories. According to prototype theory, perception truly is reality. This means that prototypical definitions rely heavily on context and are significantly subject to social flux. Bowker and Star $(1999,106)$ believe that medical classifications are "'naturally' prototypical” but they must "appear Aristotelian to bear the bureaucratic burden that is put on them.” The same can be said about library classification. However prototypical the concepts are, the underlying goal is to place one book in one place.

Can the Western mind comprehend such an inclusive theory that allows such nebulous characterizations? Does the vagueness of the group boundaries and moment-by-moment changeability render concepts meaningless? Does it mean that anyone can believe anything he or she wants? As human constructs, even in a classical framework, conceptualizations are already perception based and context sensitive, as so much classification research has shown. Since prototype theory is based on perception, adding an impossibility such as the ability to run 500 miles per hour, would unlikely be accepted by any others. That being said, prototypes need not 
be experienced to be accepted; otherwise, any new instances could not be absorbed or learned (such as seeing an ostrich for the first time and recognizing it as a bird). Minority views most likely would find difficulty gaining credence, but as a socially constructed space, if one makes an association, it can be so. In these cases, self-determination gains importance. Acts of rebellion and resistance can bring non-mainstream perceptions closer to a prototype. Different ideological conceptualizations could be equally valid, which can be both valuable and dangerous.

The concepts of sex and gender as imagined using the prototype theory of concepts as a theoretical framework provides structural flexibility and inclusiveness. The "family resemblance" stabilizes terms enough to recognize the overarching idea, allows variation in particular instantiations and accommodates overlap. However, does it provide enough stability to manage the "bureaucratic burden" required of it? Does the contextual sensitivity destroy any chance at constancy? Can it complement classical theory without losing the flexibility that makes it valuable? While prototype theory might work in theory, it can be manipulated to further offensive definitions as easily as desirable definitions. Further investigation is necessary to determine whether those obstacles can be overcome and how that flexibility could be sustained in a practical environment.

\section{References}

Alcoff, Linda. M. 2005. The metaphysics of gender and sexual difference. In B.S. Andrew, J. Keller, and L.H. Schwartzman (Eds.), Feminist interventions in ethics and politics: Feminist ethics and social theory. Lanham, MD: Rowman \& Littlefield. 17-39.

Blackless, Melanie, Charuvastra, Anthony, Derryck, Amanda, Fausto-Sterling, Anne, Lauzanne, Karl, and Ellen Lee. 2000. How sexually dimorphic are we? Review and synthesis. American Journal of Human Biology 12: 151-166.

Chow, Rey. 1993. Writing diaspora: Tactics of intervention in contemporary cultural studies. Bloomington, IN: Indiana University Press.

Dahlberg, Ingetraut. 1995. Conceptual structures and systemization. International Forum on Iinfomration and Documentation 20(3): 9-24.

Frye, Marilyn. 2005. Categories in distress. In Feminist interventions in ethics and politics: Feminist ethics and social theory, B.S. Andrew, J. Keller, and L.H. Schwartzman, eds. Lanham, MA: Rowman \& Littlefield. 41-58.

Hale, Jacob. 1996. Are lesbians women? Hypatia, 11(2): 94-121.

Haslanger, Sally. 2000. Gender and race: (What) are they? (What) do we want them to be? NOÛS, 34(1): 31-55.

Hjørland, Birger. 2009. Concept theory. Journal of the American Society for Information Science and Technology, 60(8): 1519-1536.

Jacob, Elin. K. 2004. Classification and categorization: A difference that makes a difference. Library Trends, 52(3): 515-540.

Margolis, Eric, and Laurence, Stephen. 2006. Concepts. Stanford encyclopedia of philosophy. http://plato.stanford.edu/entries/concepts

Mikkola, Mari. 2009. Gender Concepts and Intuitions. Canadian Journal of Philosophy 39 (2): 559-583 

ed. Proceedings from North American Symposium on Knowledge Organization, Vol. 3. Toronto, Canada, pp. 151-159.

Nye, Andrea. 1990. Words of power: A feminist reading of the history of logic. New York: Routledge.

Olson, Hope A. 1999. Exclusivity, teleology and hierarchy: Our Aristotelian legacy. Knowledge Organization, 26(2): 65-73.

Olson, Hope A. 2001. Sameness and difference: A cultural foundation of classification. Library Resources and Technical Services, 45(3): 115-122.

Olson, Hope A. 2007. How we construct subjects: A feminist analysis. Library Trends, 56(2): 509-541.

Rosch, Eleanor. 1999. Reclaiming cognition: The primacy of action, intention and emotion. The Journal of Consciousness Studies, 6(11-12): 61-77.

Slaughter, Mary M. 1982. Universal languages and scientific taxonomy in the seventeenth century. New York: Cambridge UP.

Szostak, Rick. 2004. Classifying science: Phenomena, data, theory, method, practice. Norwell, MA: Springer.

Szostak, Rick. 2010. Comment on Hjørland's concept theory. Journal of the American Society for Information Science and Technology, 61(5): 1076-1077.

Wittgenstein, L. 1988. Philosophical Investigations ( $3^{\text {rd }}$ ed.). Trans. G.E.M Anscombe. London: Basil Blackwell (1953). 